Cómo citar este artículo en MLA: Misseri, L. "Utopía y derecho: un argumento en favor del reconocimiento de su vínculo". Escritos 27.58 (2019): 119-139. doi: http://dx.doi.org/10.18566/

\title{
Utopía y derecho: un argumento en favor del reconocimiento de su vínculo
}

\author{
Utopia and law: argument in favor \\ of acknowledging their link
}

Utopia e direito: um argumento em favor do reconhecimento de seu vínculo

\author{
Lucas Emmanuel Misseri ${ }^{1}$
}

1 Doctor en Filosofía por la Universidad Nacional de Lanús, Argentina. Actualmente Profesor Visitante en el Departamento de Filosofía del Derecho y Derecho Internacional Privado de la Universidad de Alicante, España. Miembro del grupo de Investigación Histopía de la Universidad Autónoma de Madrid: proyecto "Historia del futuro: la utopía y sus alternativas en los horizontes de expectativa del mundo contemporáneo, siglos XIX-XXI. (I+D HAR2015-65957-P)”. Correo electrónico: lucas.misseri@ua.es. 


\title{
RESUMEN
}

La idea central de este trabajo es que hay un vínculo de complementariedad entre utopía y derecho. El principal objetivo es mostrar, a partir de un análisis conceptual e histórico, que negar ese vínculo supone al menos una visión confusa del concepto y sesgada de su devenir histórico. Para sostener dicha tesis se ofrece una tipología de las utopías, una definición estipulativa de utopía y la explicitación de dos supuestos que están en la base de la misma (uno económico y otro antropológico). Sobre esa base se rechaza el argumento de la utopía como subversiva y como perfeccionista a partir del reconocimiento de dos modelos históricos distintos de utopía: la utopía cerrada y la utopía abierta. Finalmente, se concluye que las posibles tensiones entre utopía y derecho han sido superadas a partir de la idea de un modelo abierto de utopía.

Palabras clave:

Utopía, Sistema político, Ideología, Liberalismo, Sistemas jurídicos.

\begin{abstract}
The main idea of the article is that there is a complementary link between utopia and law. Thus, the purpose is to show, through a conceptual and historical analysis, that denying such a link, at least, means the existence of an unclear and biased view of the concept of utopia and its historical development. For this purpose, it presents a provisional definition of utopia along with two assumptions underlying such definition: an economical and an anthropological one. It also presents a typology of utopias. Based on this, the idea that utopia is both subversive and perfectionist is rejected by acknowledging two different models of utopia: closed and open utopias. It is concluded that possible tensions between utopia and law are overcome by means of an open model of utopia.
\end{abstract}

\section{Key Words:}

Utopia, Political Systems, Ideology, Liberalism, Legal Systems.

\section{RESUMO}

A ideia principal desse artigo afirma que há um vínculo de complementaridade entre utopia e direito. O principal objetivo é mostrar, a partir de uma análise conceitual e histórica, que negar esse vínculo supõe, no mínimo, um olhar vago do conceito e um olhar enviesado de seu devir histórico. Para defender essa tese se oferece uma tipologia das utopias, uma definição estimativa da utopia e o desenvolvimento de dois pressupostos que estão no fundamento da mesma (um pressuposto econômico e um pressuposto antropológico). Por conseguinte, rejeitase o argumento da utopia como subversiva e como perfeccionista a partir do reconhecimento de dois modelos históricos distintos de utopia: a utopia fechada e a utopia aberta. Finalmente, conclui-se que as possíveis tensões entre utopia e direito têm sido superadas a partir de um modelo aberto de utopia.

Palabras chave: utopía, sistema político, ideología, liberalismo, sistemas jurídicos. 


\section{Introducción}

La principal motivación de este artículo viene dada por el siguiente pasaje del filósofo del derecho Manuel Atienza Rodríguez: "Es bien significativo [...] el hecho de que tanto las utopías (desde Platón a Marx) como las antiutopías (como las de Huxley o las de Orwell en el siglo XX) coinciden en ofrecernos modelos de sociedad en los que no hay propiamente lugar ni para el Derecho ni para los juristas." (El sentido del Derecho 31). Antes de iniciar el desarrollo crítico del mismo, es importante aclarar que se reconoce que Atienza no es un experto en el estudio de las utopías y el libro citado es de carácter introductorio. No obstante, por lo que representa su obra en la filosofía del derecho, se decidió emplear dicha cita como un caso paradigmático de la visión de muchos iusfilósofos con respecto a las utopías.

Otro ejemplo que puede darse viene de la iusfilosofía anglosajona, y parece ser la conclusión a la que arriban investigadores estadounidenses como Austin Sarat, Lawrence Douglas y Martha Merrill Umphrey cuando en la compilación de trabajos en torno al vínculo entre derecho e imaginación utópica afirman que: "[...] el derecho parecería jugar un rol importante, sino necesario, en la concreción de cualquier proyecto utópico. Y sin embargo, al contrario, la imaginación utópica ha desplegado hostilidad hacia las formas y procesos legales" (4).

Es curioso que tanto un filósofo como Manuel Atienza Rodríguez, que confía en el poder transformador social del derecho, como sus colegas al otro lado del Atlántico, que explícitamente buscan describir los vínculos entre la literatura utópica y el derecho, parecen convenir cada uno desde su perspectiva en que no ha habido espacio para el derecho en las utopías. El objetivo de este artículo es disputar esa convención. Aquí se sostiene la tesis de que sí hay un vínculo entre utopía y derecho, y que ese vínculo fue transformándose a lo largo de la historia -en especial desde principios del siglo XX- del mismo modo que se transformaron individualmente los estudios de la utopía y del derecho.

Otra aclaración importante es que el presente trabajo no es el primer intento de hacer notar este vínculo entre utopía y derecho; en España está el caso de Miguel Ángel Ramiro Avilés. Este iusfilósofo ha llevado adelante esa tarea desde distintos frentes, primero defendiendo que la utopía es el único modelo 
ideal de sociedad compatible con el derecho -en "La utopía de Derecho" y en Utopía y Derecho-; y luego exponiendo las principales críticas que encuentra en el pensamiento utópico hacia los sistemas jurídicos- en "La crítica al sistema jurídico"-. Crítica que por supuesto no anula el vínculo entre ambos conceptos. No obstante, aquí se ofrecerá un argumento afín pero distinto al de Ramiro en favor de este vínculo que amerita una mayor indagación conceptual. Oportunamente se señalarán cuáles son esos puntos de contacto entre ambos argumentos, pero se anticipa que sobre todo el punto de contacto tiene que ver con lo que más adelante se denominará el "supuesto económico de la utopía".

El vínculo entre utopía y derecho puede ser estudiado desde dos perspectivas claramente definidas. Por un lado, se puede describir el rol que juegan los elementos jurídicos en ciertas utopías concretas. Por otro lado, se puede analizar el rol que juega el utopismo en ciertos ordenamientos jurídicos y en la fundamentación de ciertos tipos de derechos, como por ejemplo los derechos humanos. Aquí solo se abordará la primera perspectiva que parece ser la menos frecuentada, si se la compara con los múltiples trabajos que dan cuenta de lo segundo en un sentido amplio del término "utopía". Tal es el caso de los trabajos de Fernando Alcantarilla Hidalgo en relación al utopismo en las distintas generaciones de derechos humanos; Jürgen Habermas cuando se refiere a los derechos humanos como "utopía realista"; la edición de Ramiro Avilés y Cuenca Gómez en torno a utopía y derechos humanos; o el trabajo de Samuel Moyn sobre el mismo tema, por citar algunos ejemplos.

Para brindar apoyo al argumento del vínculo entre utopía y derecho desde la mencionada perspectiva se aducirán aquí dos tipos de razones. En primer lugar, se buscará clarificar el concepto de utopía procurando dar cuenta del amplio campo semántico que tiene y la diversidad de enfoques que lo abordan. Para ello se ofrecerá una tipología de las utopías hasta arribar a una definición estipulativa. A partir de esta se reconocerán dos supuestos que están a la base de la misma, uno económico y otro antropológico, ambos claramente compatibles con el derecho. En segundo lugar, se darán algunos ejemplos concretos de utopías literarias en las cuales el derecho cumple un rol importante, aunque con grados variables de juridicidad.

¿Por qué dedicar tiempo a defender este vínculo? Porque concienciar sobre el papel que cumple la imaginación utópica en la aceptación o rechazo de 
ciertos ordenamientos sociales es relevante para cualquier pretensión de transformación social. Como reconoció un crítico de la utopía, el aspecto motivacional del utopismo es una de sus principales fortalezas (Jonas 46-47).

\section{El vínculo conceptual entre utopía y derecho}

Una primera distinción que puede hacerse entre utopía y derecho tiene que ver con la carga emotiva de los términos. Si se acepta con Carlos Nino que el término "derecho" tiene una carga emotiva "favorable" (16), con el término "utopía" parecería ocurrir lo opuesto. Tal es así que algunos autores sostienen que en nuestro tiempo existe una falacia ad utopiam y un cierto grado de utopofobia. Con la falacia ad utopiam, la filósofa argentina Graciela Fernández se refiere al hecho de que en contextos discursivos decir que una idea es "utópica" o "una utopía" parece desacreditar inmediatamente a quien la sostenga.

Con el neologismo "utopofobia", el filósofo estadounidense David Estlund hace referencia al amplio rechazo en la filosofía política contemporánea a toda teoría que tenga rasgos ideales o escasa factibilidad, independientemente de que pueda cumplir un rol regulativo o evaluativo. De este modo, es al menos comprensible por qué en cualquier discurso en torno al derecho podría buscarse el mantener su separación de todo rasgo del que pueda presumirse algún grado de utopismo. No obstante, lo que afirman los autores que fueron citados como epígrafe de este trabajo es más fuerte que eso; afirman que no hay utopías en las cuales haya un espacio adecuado para el derecho. Cabe entonces preguntarse ¿qué se entiende por utopía?

Coloquialmente la palabra utopía refiere en algunos casos a un "sueño en la vigilia" y en otros a un proyecto imposible. Autores notables, como el filósofo alemán Ernst Bloch al hablar de Wachtraum en su Geist der Utopie o el politólogo estadounidense Lyman Tower Sargent al traducirlo como social dreaming, dieron cuenta del primer sentido coloquial. Y otros, como el filósofo Herbert Marcuse en sus conferencias sobre El fin de la utopía, dan cuenta del segundo. En cambio, dentro del resto de los abordajes en que no se hacen eco del sentido coloquial, no hay una definición unificada del término. Los que se reconocen son fenómenos y textos considerados utópicos, y que 
han sido analizados desde distintos enfoques disciplinares. Por ello es que a continuación se irá desde los tipos de utopías hasta una definición estipulativa de la misma que intente dar cuenta de esa variedad de sentidos.

En primer lugar, para un estudioso de la literatura, una utopía es ante todo un género literario con ciertas características definidas, que surge con Tomás Moro en el siglo XVI, quien en su obra epónima además de acuñar el término define gran parte de las características que serán repetidas hasta nuestros días: la figura de un fundador-legislador, una sociedad ordenada, un viajero que puede atestiguar las diferencias entre el Estado utópico y su tierra natal, etc. Desde la perspectiva de la utopía literaria algunos expertos sostienen que ni Platón ni Karl Marx fueron autores de utopías, dado que sus textos no cumplen las características formales que conforman el género literario. De este modo, un autor, como el experto en literatura comparada franco-rumano Alexandre Cioranescu, da razones en su Ĺavenir du passé para decir que dos de los cuatro ejemplos que ofrece Atienza no son utopías en sentido estricto, sino utopías en un sentido lato. $\mathrm{O}$ como lo pone el propio Cioranescu en relación con la obra de Platón, "La República es una obra utópica, pero no una utopía" (81).

En segundo lugar, si se toma la perspectiva de un sociólogo, el estudio más interesante no es aquel que constituye un texto de ficción con ciertas características, sino las llamadas comunidades utópicas o intencionales. Es decir, aquellas comunidades unidas en torno a un cierto ideal social. El paradigma de este modo de concebir la utopía comunitaria es la obra del sociólogo Karl Mannheim quien opuso los conceptos de ideología y utopía y entendió a esta última como todo impulso de transformación social: “[...] llamaremos utópicas a aquellas orientaciones que trasciendan la realidad y que, al informar la conducta humana, tiendan a destruir parcial o totalmente, el orden de cosas predominante en aquel momento" (260-261). De modo que desde este enfoque sí podría incluirse a Marx, pero hay dudas sobre si incluir a Platón, Huxley u Orwell.

En tercer lugar, si se toma la perspectiva de un filósofo político, ya no importa si el texto que se considera una utopía cumple con los requisitos del género literario, ni siquiera si los ideales sociales que se describen son llevados a la práctica, sino la fundamentación racional de los mismos. Podrían denominarse utopías teóricas en tanto que el fin de estas es justificar ciertos proyectos de diseño institucional de una sociedad $u$ ofrecer un marco para 
evaluar y criticar dichos diseños. En este caso, Platón y Marx sí serían buenos ejemplos porque de sus trabajos se pueden extraer teorías de la justicia que fundamentan un proyecto de sociedad. Ahora bien, los que quedan fuera son Huxley y Orwell porque, al menos en sus obras asociadas al utopismo (en particular al subgénero de las distopías), predominan rasgos ficcionales por sobre la descripción de posibles principios de diseño institucional. Aunque podría aducirse que dichos principios podrían inferirse, pero no solo no están explícitos sino que parecen ser defendidos por sus autores. En 1984 hay dos casos de expresión de principios políticos que no se adscribirían al autor. Por un lado, el breve tratado incluido como excursus en la novela que se titula Teoría y práctica del colectivismo oligárquico del ficticio Emmanuel Goldstein, inspirado en Trostky. Por otro lado, el apéndice con Los principios de neolengua como un control ideológico realizado a través de la reforma del lenguaje.

En cuarto y último lugar, está la perspectiva utopológica o de los estudios de la utopía, que intenta aunar los aportes de las distintas disciplinas, además de las ya mencionadas. La historia de las ideas ha contribuido abundantemente a estos estudios. El problema está en cómo dar cuenta de estos múltiples abordajes del fenómeno utópico en una única definición. Un intento muy modesto podría ser: una utopía es una representación de un cierto diseño de sociedad ideal. Se elige el término representación y no ficción porque tanto los utopianos imaginarios como los miembros de una comunidad utópica representan la sociedad diseñada por los utopistas. Hablo de cierto diseño y no del diseño del utopista, porque en el caso de la utopía literaria ese diseño de sociedad puede ser defendido por el autor utópico (en ese caso hablaríamos de una eutopía) o exhibido hiperbólicamente en su absurdo y crueldad (en ese caso hablaríamos de distopía). Se añade diseño "de sociedad" porque los ideales individualistas no constituyen utopías en ninguno de los tres tipos de utopías arriba descritos, solo son compatibles con el sentido coloquial del término en el que se equipara al sueño hedonista individual a la utopía. Esos ejercicios de la imaginación se acercan más a la Unomía descrita por Cioranescu ("Utopia" 96) o a los clasificados por Ramiro Avilés como "sociedades ideales anómicas" ("La utopía de Derecho" 431) en los que la imaginación representa la satisfacción de las necesidades más básicas del ser humano sin dar cuenta de la interacción social o de la complejidad de las sociedades reales.

Asimismo, en el caso de la utopía literaria, que es el que ocupará la tercera sección de este artículo, esa representación puede proyectarse en una sociedad 
imaginaria del presente en un espacio alternativo " $u$-topos" o en un tiempo alternativo "u-khronos" de donde viene ucronía, que es considerada un subgénero utópico. Es curioso que el mismo filósofo español que cuestiona el vínculo entre utopía y derecho, Manuel Atienza Rodríguez, se inspirara en la ucronía para redactar "Una apología del derecho". Esto quizá porque la diversidad y falta de unidad de los estudios de la utopía no siempre permiten asegurar que se está hablando del mismo concepto. Por ello, con una finalidad heurística se exponen los dos supuestos que, al entender del autor de este trabajo, constituyen una concepción consistente de lo que es una utopía y completan la definición estipulativa arriba sugerida: el supuesto económico y el supuesto antropológico.

Por un lado, el supuesto económico tiene que ver con el hecho de que las utopías aceptan que las necesidades son ilimitadas pero los recursos son limitados. En palabras del historiador inglés James Colin Davis, “[...] el utópico es más «realista» o tozudo, ya que acepta el problema básico tal como es: satisfacciones limitadas expuestas a carencias limitadas" (46). Este supuesto toma la forma del requisito de verosimilitud en la utopía literaria según Cioranescu en tanto que: "El utopista debe respetar la lógica de los hechos, un poco como el historiador" (L'avenir 25). Recientemente el filósofo argentino Fernando Lizárraga sostuvo algo similar al decir que en la Utopía de Moro y en las utopías en general "se observa un fuerte apego al realismo y la verdad" (124).

Por otro lado, el supuesto antropológico se basa en el hecho de que las utopías confían en la capacidad de transformar las condiciones materiales del vínculo social a partir de la razón y la voluntad humanas. Contra la idea de utopía como sueño, sostiene Cioranescu que la utopía "en su calidad de vehículo de ideas invita a la reflexión más bien que al sueño y no solicita la imaginación más que para aplicarla y reducirla a la razón" (L’avenir 12).

El filósofo Guillermo Lariguet llamó mi atención sobre el vínculo entre los supuestos señalados y algunos de los denominados "contenidos mínimos del Derecho natural" en la obra de Herbert L. A. Hart, en especial el que remite a los recursos limitados pero también el altruismo limitado (242). La idea de altruismo limitado está en la base del supuesto antropológico; y en el caso de Ramiro Avilés, se asocia a las condiciones básicas de justicia desarrolladas por David Hume, según las cuales no puede haber justicia donde haya abundancia 
de bienes materiales o altruismo ilimitado ("La utopía de Derecho" 440). Algo que también comparte Lizárraga en relación con la utopía de Moro cuando dice "Utopía es posible porque no se sitúa ni en escenarios de plena abundancia material ni de hipersocialización, lo cual genera circunstancias donde pueden emerger principios distributivos" (124-125). Aquí se suscribe una parte de las condiciones humanas -la necesidad de que haya un mínimo de condiciones materiales- para garantizar la viabilidad de ciertas instituciones. Pero se permite dudar de la no necesidad de principios de justicia aún en contextos de abundancia de bienes materiales, dado que estos podrían juzgar un rol importante para dirimir ciertos conflictos además de un rol epistémico de explicitar qué hacer en ciertas situaciones. No obstante, desarrollar ese argumento es tarea para otro artículo.

Recapitulando lo sostenido hasta aquí, estos dos supuestos de la utopía permiten dar cuenta del modo más amplio posible sobre qué se entiende por este concepto y, sobre todo, qué no, porque desde la ampliación del término a partir de los estudios sociológicos de la utopía se ha hecho difícil especificar qué no es una utopía. Una utopía no es un mito, una utopía no es una fantasía irracional, el milenarismo no es una utopía, una sociedad alienígena o angélica tampoco constituirían una utopía, o la supervivencia en solitario en una isla tampoco lo es. Si se aceptan estos supuestos, que no parecen tener demasiada controversia en gran parte de la bibliografía utopológica, entonces es difícil pensar que la utopía pueda estar ajena a algún grado de juridicidad. En otros términos es difícil pensar que el derecho no tenga lugar en la utopía, ya que, por un lado, el supuesto económico demanda alguna forma de organización para gestionar los recursos de acuerdo a ciertas necesidades, lo cual demanda a su vez criterios de justicia distributiva y el establecimiento de autoridades que los determinen. Por otro lado, el segundo criterio condiciona a que los mismos surjan de la razón humana y por tanto demandan cierta normatividad, ya sea procedimental para asegurar que los criterios sean elegidos según ciertas pautas, o sustantiva en tanto que se busca proteger ciertos valores.

Ahora bien, la distinción entre lo racional y lo razonable de Ralws puede ser orientadora sobre esto último. En los ordenamientos jurídicos de las utopías literarias tempranas -a los que en la próxima sección se denominarán "modelos cerrados" - se daba un criterio racional pero no necesariamente razonable, en tanto que no había espacio para otras concepciones sobre lo bueno que la ya 
legitimada en el acto fundacional de dicha utopía. En la siguiente sección se abordarán algunas objeciones ante este planteo precisando mínimamente qué se entiende aquí por derecho.

\section{La objeción del aspecto subversivo y perfeccionista del utopismo como rasgos antijurídicos}

Llegado este punto cabe preguntarse qué se entiende por derecho. Una definición mínima de derecho objetivo podría ser: conjunto de normas aceptadas en mayor medida por una comunidad definida espacio-temporalmente, tendiente a regular la conducta de sus miembros y a establecer las autoridades que se encargan de que dichas normas sean respetadas para conservar cierto orden social. Se podrían reconocer tres dimensiones analíticas atribuibles a la Escuela alicantina de Filosofía del Derecho (de la que es miembro fundador el ya mencionado filósofo Atienza Rodríguez): una dimensión regulativa, una institucional y una axiológica. Estas tres dimensiones jurídicas se hallan representadas en mayor o menor medida en las utopías literarias, dado que dan cuenta de normas regulativas que rigen la conducta de los utopianos para instarlos a cooperar, aunque no siempre tengan dicha inclinación.

Hay normas constitutivas que establecen los distintos órganos jurídicos, aunque es cierto que hay una crítica especial al colectivo de los abogados, los cuales o se ven reducidos en su número o la profesión de abogado en tanto que mediador es omitida en favor de la representación directa de los implicados en conflictos jurídicos. Véase por ejemplo el caso de la Utopía de Moro, en la cual siendo el propio Moro abogado de formación excluye a este grupo (159). En última instancia hay un elemento axiológico que es relativamente claro: una moral que permite la conservación de dicho ordenamiento cultivada a partir de estrategias como la educación además de las sanciones, y que busca fundamentarse en la razonabilidad de los mismos. En el caso de Moro, hay quienes argumentan que los principios de austeridad y de "vivir según la naturaleza" son de tipo helenístico, y más precisamente de cuño epicúreo (Surtz).

Ahora bien, si se revisa el rol del derecho en la conservación de un cierto orden social, inmediatamente se percibe la contradicción que puede haber entre utopía en el sentido dado por los sociólogos y esta definición mínima de 
derecho. Parecería que el Derecho tendría una tendencia hacia la conservación de un cierto estado de cosas social y la protección de ciertos bienes colectivos, mientras que en el planteo de Mannheim se entiende a la utopía desde una perspectiva subversiva, como una pulsión de cambio social y una crítica del ordenamiento vigente diagnosticado como injusto y apoyado por una cierta ideología imperante. Es cierto que este enfoque tiene sus críticos (Cioranescu, Zuolo) pero en muchos aspectos sigue vigente.

Por lo anterior, cabe preguntase que: ¿puede separarse completamente el concepto de utopía del de ideología como dos polos opuestos? Dentro de los estudios de la utopía hay varios autores que han sostenido la tesis de la complementariedad entre ambos. Matizando el aserto de Mannheim que pone a uno como pulsión de cambio y a otro como el de pulsión de conservación. Esta idea de complementación entre utopía e ideología permite entender cómo hay utopías conservadoras, utopías reaccionarias e ideologías del cambio constante. Entre quienes sostienen esta tesis se encuentra Ricoeur, quien lo hace en sus conferencias homónimas a las de Mannheim (ctd en Ramiro Avilés, "Ideología y utopía"), de cuya postura se hace eco en Ramiro Avilés. Al mismo tiempo ocurre algo similar en los estudios latinoamericanos de la utopía con la obra de Horacio Cerutti Guldberg (109) y sus discípulos (Ramírez Fierro). Ejemplos literarios que dan cuenta de que estas pulsiones de cambio del Estado de cosas no siempre se proyectan como una innovación o una transformación genuina, sino más bien como una restauración de un estado de cosas anterior moralmente superior, viene dado por algunas interpretaciones de la utopía de Moro. Donde, por ejemplo, el comunismo es visto como una reacción ante el incipiente capitalismo pero no como superación sino desde una mirada retrospectiva hacia las comunidades de los primitivos cristianos. $\mathrm{O}$ por ejemplo en el caso de la teocracia defendida por Campanella en su Ciudad del $\mathrm{Sol}$, concebible como una reacción con tintes milenaristas y astrológicos ante el absolutismo de los reinos de la época de la Contrarreforma.

En otras palabras, lo que se sugiere es que las utopías están cargadas de supuestos axiológicos, de valoraciones sobre lo bueno, que no siempre presuponen la superación de las estructuras jurídicas tradicionales sino más bien que pueden ser miradas nostálgicas a un pasado que no siempre es remoto, por lo cual no se trata de un pasado necesariamente prejurídico. Tal es el caso del influjo de la idealización de la República romana que influye no solo en Moro sino también en un utopista del siglo XVII como James Harrington en su República 
de Océana de 1656, cuya obra es considerada una utopía literaria para algunos, y para otros una utopía teórica por el detalle con el que describe su plan de reforma agraria y de gobierno mixto para esa Inglaterra alternativa que es Océana.

El punto es que el concepto de utopía no está necesariamente atado a una idea de revolución en tanto que superación ideológica. Muchas veces se trata de reformas técnicas, religiosas, agrícolas. Es cierto que hay cierta radicalidad en los cambios utópicos, como sostiene Ramiro ("Ideología y utopía" 92) pero de algún modo los supuestos económico y antropológico sumados a la dificultad de anticipación hacen que en muchos casos los utopistas se vean limitados en sus propuestas. En muchos casos reproducen instituciones tal cual están, pero establecen una serie de requisitos procedimentales para evitar que se caiga en las conductas indeseadas. Podría decirse que Moro es radical en cuanto a la institución de la propiedad, pero poco innovador en cuanto a la institución de la familia. Si en Utopía la propiedad es común, en el marco de la familia la autoridad indiscutida la sigue teniendo el pater familias. Es inevitable que en su ejercicio imaginativo los utopistas miren hacia el pasado, pero es la pregunta por la mejora social y las limitaciones de los supuestos antedichos las que estructuran las utopías.

La pregunta guía para valorar las utopías es qué tipo de ideal se representa en ellas. El mismo Mannheim da ejemplos de utopías dispares en los que se nota la diversidad ideológica: incluye a las comunidades anabaptistas de Europa a comienzos de la modernidad (confundiendo milenarismo con utopía), a la mentalidad utópica humanitaria-liberal, la conservadora y finalmente la socialista comunista (parte II, cap. III). Más moderado y tal vez más verosímil que decir que la utopía se contrapone a la ideología sea decir que toda utopía lleva adelante una función de crítica social, ya sea por un contraste ficcional (utopía literaria), ya sea por la descripción de los principios por los que debería regirse la sociedad (utopía teórica), o por la intención de formar una comunidad diferente (utopía comunitaria). Todos los utopistas están situados espacio-temporalmente en una sociedad que les sirve de contramodelo para imaginar los rasgos, principios o acciones que constituyen su diseño social. Es por ello que las utopías cumplen un papel relevante de motivación para la transformación social, pero también de testimonio de los distintos ideales societarios de las diversas comunidades a lo largo de la historia. 
Una segunda objeción tiene que ver con el hecho de que se considera que las utopías ofrecen una visión de sociedad ideal en el sentido de perfección. Hay varias formas de entender la perfección aplicada a las utopías: lo perfecto puede ser el ordenamiento político o lo perfecto puede ser la conducta moral de sus ciudadanos. La segunda de estas opciones no ha sido sostenida abiertamente por los utopistas clásicos, quienes como en el caso de Moro resaltan las virtudes de los utopianos, pero no dejan de considerar a la humanidad desde un cierto pesimismo, según el cual carentes de ciertas motivaciones, como por ejemplo los castigos en esta vida o en una ulterior, los utopianos se pervertirían.

Asimismo, todas las utopías dan cuenta de algún conjunto de leyes establecidas por un fundador-legislador mítico que establece sanciones para quienes las incumplan, autoridades encargadas de hacerlas cumplir e instituciones establecidas contra aquellos que las incumplen. De modo que si las utopías constituyen una mejora con respecto al estado de cosas social no es por la perfección moral de sus ciudadanos sino por la mejora en sus instituciones. Como se dijo más arriba, una sociedad de "ángeles" no es una utopía en tanto que no da cuenta del supuesto antropológico porque son seres "no humanos", ni del económico porque no da cuenta del conflicto entre necesidades y recursos. Ahora bien, lo que algunos autores sí han aceptado es la idea de perfección de las instituciones que constituyen sus utopías. Por eso se habla del carácter ahistórico de las utopías, porque la realización de la utopía parece suponer su propia clausura. O dicho de otro modo, no hay espacio para los utopistas entre los utopianos. Esta es una característica sobre todo de un cierto período en la historia de las utopías que va desde el Renacimiento hasta entrada la Modernidad. Pero desde el siglo XVIII en adelante, con la idea de progreso, no sólo prospera la forma ucrónica de las utopías (utopías proyectadas en el futuro) sino que la idea de perfección se convierte en la de perfectibilidad. Así podría distinguirse entre las utopías literarias que presentan un modelo cerrado y las que presentan un modelo abierto al cambio o como dice Fernando Mosquera "mirando al horizonte de la historia" (133). H. G. Wells llamó utopías clásicas o estáticas a las primeras y modernas o cinéticas a las segundas (33). El ataque de autores como Karl Popper ha mostrado los peligros del modelo cerrado de utopía, en tanto que esta establece una concepción de lo bueno de modo autoritario y parece impedir todo cambio. No obstante, como se verá a continuación, esas críticas no valen para la utopía de modelo abierto, incluso en cierto modo su defensa de la sociedad abierta puede ser 
interpretada en sentido amplio como una utopía teórica que ve en ciertos valores del liberalismo el ideal de sociedad.

Si bien el modelo cerrado de utopía es el que ha sido más criticado en términos políticos, al mismo tiempo es aquel en el que, al menos en las utopías literarias, más claramente se ve el papel del derecho objetivo a partir de la descripción de sociedades imaginarias en algunos casos hiperreguladas. Los compiladores de Law and the Utopian Imagination consideran que una de las principales razones de la ausencia de más estudios sobre el vínculo entre utopía y derecho se basa en el hecho del éxito del "antagonismo entre el utopismo y la legalidad liberal". Entre los defensores de la legalidad liberal además de Popper incluyen a Isaiah Berlin y a Lionel Trilling. No obstante, no todo los defensores del liberalismo se han manifestado como antagónicos de la utopía. Como contraejemplo a lo que sostienen estos autores se puede citar a John Rawls con su idea de "utopía realista" y a Robert Nozick con la de "la utopía marco", pero es cierto que sus obras se enmarcan en un contexto posterior, en especial The Law of Peoples de Rawls publicada después del fin de la Guerra Fría.

Los ejemplos de utopías que Sarat, Douglas y Umphrey consideran hostiles al derecho son la República de Platón para quien la sabiduría de los guardianes reemplazaría al derecho (coincidiendo con el ejemplo de Atienza Rodríguez), y Walden Dos de Burrhus F. Skinner, donde el conductismo entendido como una serie de estímulos negativos y positivos adaptables a las necesidades de la comunidad reemplazarían el ordenamiento jurídico. Incluso los críticos Sarat, Douglas y Umphrey reconocen que la isla imaginaria de Moro es mayormente un "Estado de derecho" (1). Pero no parecen tener en cuenta, en la obra de Moro, el perjuicio desde el punto de vista del derecho subjetivo, es decir, desde la perspectiva de los sujetos de derecho, quienes en su mayoría carecen de la posibilidad de expresarse libremente en temas de política (salvo que sean funcionarios) y la existencia de la esclavitud como una forma de castigo institucionalizado. Como se dijo más arriba, el modelo cerrado tiene que ver también con intentos de ordenamiento acordes a lo que proyecta un utopista situado espacio-temporalmente. Por lo cual sería anacrónico, o al menos muy optimista, esperar que Platón, Moro o Campanella den cuenta de nuestro listado de derechos humanos, aunque no sería absurdo esperarlo de Skinner. Recapitulando, es cierto que ha habido ciertos desencuentros entre algunas propuestas utópicas y el derecho entendido como protección de ciertos bienes básicos humanos, pero esto no parece ser una característica necesaria 
del pensar utópico sino más bien un hecho contingente. En otros términos, tiene que ver con el modo en el que los utopistas resolvieron el desafío de proponer un Estado mejor que el suyo pero constreñidos por ciertos límites racionales e históricos que condicionaron su ejercicio de imaginación crítico. A continuación se analizarán algunos casos de modelos abiertos de utopía más cercanos en el tiempo, como contraejemplos de ordenamientos jurídicos imaginarios que no solo dan cuenta de la perspectiva estática del derecho sino también de la dinámica.

\section{Las utopías modernas como modelos abiertos}

Por "modelo abierto" se entiende aquí la posibilidad de aceptación del disenso y de modificación, corrección o adaptación de las instituciones básicas que constituyen la representación de un cierto diseño de sociedad que denominamos utopía. Herbert George Wells fue uno de los primeros en advertir el escaso movimiento y espacio para el disenso que presentaban las utopías literarias clásicas, por lo cual procuró describir en su Utopía moderna de 1905 una utopía cinética que aquí denominamos "abierta". Ella tiene algunos rasgos notables que marcan un gran cambio epocal: a diferencia de las utopías clásicas, Utopía moderna es global en lugar de insular (Wells 37); los utopianos modernos reconocen la propiedad privada e incluso miden el grado de libertad de sus habitantes a partir de su poder adquisitivo (95); se permite el disenso político (118) y no se establece como una sociedad perfecta sino como una perfectible.

No obstante, pese a los esfuerzos por dar cuenta de cierta apertura en esa utopía, hay una élite que detenta el poder: los samuráis (217), los disidentes son una especie de parias que opinan pero no son tomados en serio o son directamente recluidos en islas (133-135) y hay un libro único que establece los pasos a seguir para la perfectibilidad. Ese "Libro del Samurái" no es propiamente una constitución porque incluye también datos científicos, pero oficia como tal en tanto que da los parámetros para juzgar las conductas de los funcionarios y el resto de los ciudadanos (230-236).

La obra de Wells constituye un hito en la historia de las utopías porque ha realizado una tarea de autocrítica dentro de la utopía. La intertextualidad de Utopía moderna es notable porque no solo es una novela sino que es 
un ensayo crítico de las utopías en las que además de las clásicas de Moro, Campanella y Bacon, se menciona otra generación de utopistas que incluye autores como Cabet o Hertzka (Wells 36). Wells, de algún modo, es el padre de la distopía del siglo XX, dado que los grandes autores de ese subgénero se inspiraron directamente en su obra. Pero la intención de Wells no es solo ser una crítica del utopismo, sino que intenta de algún modo dar cuenta de la parte propositiva, de ofrecer la primera de una nueva serie de utopías abiertas. No obstante, hay buenas razones para decir que no tiene éxito en tanto que el carácter de parias de los disidentes recuerda bastante a los utopianos clásicos de Moro, entre los que los ateos y aquellos que no creen en la inmortalidad del alma se ven excluidos de la administración pública, por ser considerados personas poco confiables (188). No obstante, vale repetir que a diferencia de la Utopía moderna solo los magistrados pueden opinar de política, el resto son castigados si lo hacen en público. Por lo cual, Wells hace progresos hacia utopías más abiertas y su texto es más una invitación a pensar la utopía de otro modo que un buen ejemplo de ese nuevo modo de pensarla.

Wells llamaba al estudio de las utopías "utopografía" (ctd en Parrinder 117) y consideraba que este debía ser el método de la sociología (ctd en Levitas xi). Wells estaba convencido de que la utopía era un excelente método para la mejora de la sociedad. Por ello sostenía que la sociología, a la que imaginaba más normativa que descriptiva, debía tomar a la utopía como herramienta metodológica, y que era necesario combatir la entropía de la naturaleza con la acción humana, más precisamente con la acción moral institucionalizada. Como se anticipó más arriba, Wells no solo escribió textos utópicos sino también distópicos. Las distopías son representaciones de sociedades ideales con cuyos ideales no se comulga. Por ejemplo en las tres obras mencionadas se critican la homogeneidad, la excesiva regulación, la concentración del poder y, en general, la ausencia de los más básicos derechos humanos. Pero aquí hay un problema si citamos a las distopías como ejemplos de la ausencia de vínculo entre utopía y derecho: ¿cómo refuerzan esa tesis? Si se plantea que las sociedades distópicas son sociedades opresivas e hiperreguladas parecería que podrían ser considerados ordenamientos jurídicos injustos, legitimados pero no legítimos.

Un caso extremo es el Día de la Unanimidad en Nosotros donde todos votan al Gran Benefactor como su único e incuestionable líder político. Podría decirse que no se trata de un sistema jurídico injusto sino que directamente no se trata de un sistema jurídico en absoluto. Esto por la arbitrariedad presente en 
dichos Estados distópicos en los que los derechos más básicos e inalienables no encuentran la más mínima protección y por tanto violan la célebre cláusula de Gustav Radbruch según la cual un ordenamiento normativo insoportablemente injusto no es derecho en absoluto sino mera fuerza. Entonces, si las distopías no son ejemplos de derecho y ponen en cuestión ciertas características negativas de las sociedades de los autores, ¿no serían entonces una defensa del derecho bien entendido? En otras palabras, si las distopías describen los pesares de los seres humanos en comunidades no-jurídicas, ¿no son entonces apologías del derecho? Por lo tanto, parecería que la utopía incluso en su vertiente distópica está al servicio de la protección de los derechos y de ordenamientos jurídicos que los garanticen.

Hay quienes afirman con buenas razones que el siglo XX fue el siglo de las distopías, no obstante, además de la controvertida Walden Dos, hay otro caso de utopía relativamente reciente: Ecotopía de Ernst Callenbach publicado por primera vez en 1975 donde se describe la secesión de una parte de los Estados Unidos de América con la finalidad de respetar ciertos bienes que no estaban suficientemente garantizados en dicho país. En este caso se trata de los derechos con respecto al medio ambiente en el que viven los ciudadanos, lo que implica un cambio no solo en el ordenamiento jurídico sino también en la educación de sus ciudadanos, dado que la una sostiene al otro y viceversa. Asimismo, en esta utopía Callenbach no solo se ocupa de un mejor ordenamiento estatal sino que hay ciertas medidas tendientes a estimular la participación ciudadana en los aspectos legislativos, como es el caso de la transmisión televisiva en vivo de las deliberaciones parlamentarias ecotopianas.

Otro caso lo constituye la obra de otro estadounidense, Kim Stanley Robinson, quien ha contribuido con sendas utopías en las que aborda los desafíos de nuestras sociedades contemporáneas y en los que el derecho juega un rol importante. En Robinson hay al menos dos escenarios ucrónicos dignos de destacar para nuestro argumento. Por un lado, el de refundación del modo de organización humana en un nuevo planeta. Este es el argumento de su trilogía marciana. Ante la inevitabilidad del desastre ya realizado en la Tierra, Marte se ofrece como una hoja en blanco para obtener no solo otra oportunidad ambiental sino moral y jurídica. Los viajeros que van a terraformar el planeta rojo desarrollan, en múltiples generaciones, un nuevo tipo de organización que se ve plasmada en una constitución jurídica propiamente dicha (Robinson, 2000). Aunque podría objetarse que presentar una utopía que implica la 
terraformación de otro planeta viola el presupuesto económico, dado que al menos en un plazo razonable, esto no parece viable ni deseable. Hay quienes afirman lo contrario, pero sus posturas son minoritarias y aún deben mostrar que los grandes desafíos técnicos que implicaría dicha empresa están a nuestro alcance. Una vez mostrado eso habría que defender por qué terraformar Marte y no reformar la Tierra.

Por otro lado, el mismo autor ha propuesto otro tipo de utopías del futuro en la cual las crisis de justicia social y climática son superadas a partir de cambios en el sistema jurídico-económico que de algún modo contienen el capitalismo (Robinson, Green Earth). La viabilidad de esto también puede ser cuestionada pero hay ciertas medidas como es el caso de la tasa Tobin que son concretas, aplicables y aplicadas y que parecen ir en una dirección similar.

Asimismo, las utopías teóricas también se hicieron eco de esta apertura que se manifestó en la literatura (Nozick, Rawls). Para Rawls la utopía global a la Wells vendría dada por una sociedad de pueblos liberales y decentes, esto último implicaría la aceptación del disenso junto a una visión minimalista de los derechos humanos. No obstante, desarrollar el vínculo entre derecho y utopías teóricas es una tarea que excede las posibilidades de este trabajo.

\section{Conclusión}

Por todo lo mencionado se reafirma que hay un claro vínculo entre el derecho y la utopía. En primer lugar, hay un vínculo conceptual porque no hay razones por las que la utopía -entendida aceptando los dos supuestos aquí estipulados- excluya al derecho, sino porque la utopía demanda alguna clase de ordenamiento normativo que excede el de la moral social por la complejidad de las sociedad representadas. En segundo lugar, hay un vínculo que se puede trazar históricamente a partir de ciertos ejemplos de utopías literarias en los que parece al menos incorrecto prima facie negar que haya lugar para el derecho. Esto porque las narraciones de Estados imaginarios que llamamos utopías literarias dan cuenta de leyes positivas reconocidas por su comunidad que buscan proteger ciertos bienes colectivos, mecanismos de mediación y sanciones externas institucionalizadas. 
Este trabajo pretendió contribuir al estudio del vínculo entre las utopías y el derecho, vínculo sobre el que aún queda mucho por explorar. Además de las utopías literarias sobre las que se hizo hincapié en este escrito, resta indagar el vínculo entre el derecho y las utopías teóricas y las comunitarias. Un caso interesante lo constituye el socialismo utópico que tiene autores mayormente ligados a utopías teóricas y comunitarias, pero que cuenta con una excepción: Étienne Cabet, quien también produjo una utopía literaria (Viaje a Icaria) y cuyas ideas intentó poner en la práctica en utopías comunitarias en los Estados Unidos. Otro aspecto interesante sería explorar el rol que juega la imaginación utópica en organismos internacionales y en entidades supranacionales como la Unión Europea. O incluso analizar la factibilidad de que las llamadas utopías transhumanistas pudieran concretarse y con ello poner en jaque el supuesto antropológico aquí enunciado como constitutivo del utopismo. Estos son solo algunos de los problemas que ponen en diálogo a la otra perspectiva del vínculo no abordada aquí, la que busca los elementos utópicos que tiene el derecho.

En ambos casos, el terreno se plantea fértil para la discusión y el desarrollo de ideas desde una perspectiva interdisciplinar, en la cual entran en juego no solo la filosofía del derecho como puente entre el derecho y la filosofía sino la sociología, la historia y la literatura. Todas estas visiones disciplinares pueden contribuir a una mejor comprensión de las representaciones ideales de sociedad que, por un lado, ofrecen un modelo con el que criticar el estado de cosas actual y, por el otro, motivan nuestro accionar colectivo y parte de nuestras expectativas presentes y futuras.

\section{Referencias}

Alcantarilla Hidalgo, Fernando José. Utopía y derechos humanos: los derechos del hombre en las sociedades ideales. Madrid: Dykinson, 2009.

Atienza Rodríguez, Manuel. El sentido del Derecho. Barcelona: Ariel, 2001.

Atienza Rodríguez, Manuel. "Una apología del Derecho". El Cronista del Estado Social y Democrático de Derecho 78 (2018): 22-29.

Bloch, Ernst. Geist der Utopia. Frankfurt: Suhrkamp Verlag, 1964.

Cabet, Étienne. Viaje por Icaria. 2 Vol. Trad. N. Monturiol y F. J. Orellana. Barcelona: Orbis, 1985.

Callenbach, Ernest, Ecotopia. Berkeley: Banyan Tree Books, 2004. 
Cerutti Guldberg, Horacio. Ensayos de utopía I y II. Toluca: Universidad Autónoma del Estado de México, 1989.

Cioranescu, Alexandre. "Utopia: Land of Cocaigne and Golden Age". Trad. S. Bradshaw. Diógenes 19. 75 (1971): 85-121.

Cioranescu, Alexandre. L'avenir du passé : utopie et littérature. Paris: Gallimard, 1972.

Davis, J. C. Utopía y la sociedad ideal. Trad. Juan José Utrilla. Ciudad de México: Fondo de Cultura Económica, 1985.

Estlund, David. "Utopophobia". Philosophy \& Public Affairs 42.2 (2014): 113-134.

Fernandéz, Graciela. Utopía: contribución al estudio del concepto. Mar del Plata: Editorial Suárez, 2005.

Habermas, Jürgen. "El concepto de dignidad humana y la utopía realista de los derechos humanos". Diánoia 55.64 (2010): 3-25.

Harrington, James. La república de Océana. Trad. E. Díez-Canedo. Ciudad de México: Fondo de Cultura Económica, 1987.

Hart, Herbert L. A. El concepto de Derecho. Trad. G. Carrió. Buenos Aires, A. Perrot, 1998.

Jonas, Hans. El principio de responsabilidad: ensayo de una ética para la civilización tecnológica. Trad. J. M. Fernández Retenaga. Barcelona, Herder, 1995.

Levitas, Ruth. Utopia as Method: The Imaginary Reconstitution of Society. Palgrave Macmillan, 2013.

Lizárraga, Fernando. "Política, justicia y comunidad en Utopía". Anacronismo e irrupción 8.15 (2018): 121-146.

Mannheim, Karl. Ideología y utopía. Trad. E. Terron. Madrid: Aguilar, 1966.

Marcuse, Herbert. El final de la utopía. Barcelona: Planeta-De Agostini, 1986.

Moro, Tomás. Utopía. Trad. R. Esquerra. Madrid: Círculo de Edición de Bellas Artes, 2011.

Mosquera Brand, Fernando Abilio. "Utopía, la posibilidad de la imposibilidad: una lectura desde Thomas More". Escritos 17.38 (2009): 125-169.

Moyn, Samuel. La última utopía: los derechos humanos en la historia. Bogotá: Ed. Pontificia Universidad Javeriana, 2015.

Nino, Carlos Santiago. Introducción al análisis del derecho. Buenos Aires: Astrea, 2003.

Nozick, Robert. Anarchy, State, and Utopia. Oxford: Blackwell, 1999.

Orwell, George. 1984. Trad. R. Vázquez Zamora. Buenos Aires: Booket, 2006.

Parrinder, Patrick. "Utopia and meta-utopia in H. G. Wells". Science Fiction Studies 12.2 (1985): 115-128.

Platón. República. Trad. A. Camarero. Buenos Aires: Eudeba, 2004.

Popper, Karl. El desarrollo del conocimiento científico. Trad. N. Míguez. Buenos Aires: Paidós, 1967.

Ramírez Fierro, María del Rayo. Utopología desde nuestra América. Bogotá: Desde Abajo, 2012.

Ramiro Avilés, Miguel Ángel. "La utopía de Derecho". Anuario de Filosofía del Derecho 19 (2002):431-460. 
Ramiro Avilés, Miguel Ángel. Utopía y Derecho: el sistema jurídico en las sociedades ideales. Madrid, Marcial Pons, 2002.

Ramiro Avilés, Miguel Ángel. "La crítica al sistema jurídico en el pensamiento utópico”. En: El Derecho en Red. Francisco Javier Ansuátegui Roig. Madrid: Dykinson, 2006. 921-949.

Ramiro Avilés, Miguel Ángel y P. Cuenca Gómez, editores. Los derechos humanos: la utopía de los excluidos. Madrid: Dykinson, 2010.

Rawls, John. The Law of Peoples with "The Idea of Public Reason Revisited". Cambridge (EE UU) y Londres: Harvard University Press, 1999.

Robinson, Kim Stanley. The Martians. Nueva York: Bantam Books, 2000.

Sarat, Austin, Lawrence Douglas y Martha Merrill Umphrey, editores. Law and the Utopian Imagination. Stanford: Stanford University Press, 2014.

Sargent, Lyman Tower. “The Three Faces of Utopianism Revisited”. Utopian Studies 5.1 (1994): 1-37.

Skinner, Burrhus Frederic. Walden dos. Madrid: Orbis, 1985.

Surtz, Edward. "Epicurus in Utopia”. ELH 16.2 (1949): 89-103.

Trousson, Raymond. Historia de la literatura utópica. Trad. C. Manzano de Frutos. Barcelona: Península, 1995.

Wells, Herbert George. Una utopía moderna. Trad. J. A. Sánchez Rottner. Barcelona: Océano/Abraxas, 2000.

Zuolo, Federico. "Some Formal Criteria to Distinguish between Utopia and Ideal Theory". Utopia and Utopianism 3 (2009): 81-93. 